\title{
Cartas e bilhetes de Otto Maria Carpeaux a Manoelito de Ornellas: filamentos de uma rede de relações intelectuais
}

\author{
Letters and notes from Otto Maria Carpeaux to Manoelito de Ornellas: \\ filaments in a web of intellectual relations \\ Pedro Theobald \\ Pontifícia Universidade Católica do Rio Grande do Sul - Porto Alegre - Rio Grande do Sul - Brasil \\ $\diamond$
}

\begin{abstract}
Resumo: Este artigo apresenta trechos comentados das cartas que Otto Maria Carpeaux escreveu a Manoelito de Ornellas entre maio de 1949 e abril de 1953. O objetivo é avaliar esta pequena parte da correspondência passiva do Acervo Literário Manoelito de Ornellas quanto às características da relação de sociabilidade intelectual que se estabeleceu entre esses dois importantes escritores: por um lado o ensaísta de formação europeia premido pelas necessidades do exílio e, por outro, o escritor local cuja vasta rede de relações lhe permite estender a mão a um confrade necessitado.
\end{abstract}

Palavras-chave: Carpeaux; Ornellas; Correspondência; Relações literárias

\begin{abstract}
This paper presents commented excerpts of the letters that Otto Maria Carpeaux addressed to Manoelito de Ornellas between May 1949 and April 1953. Its aim is to evaluate this small part of the passive correspondence contained in Manoelito de Ornellas' Literary Collection as to the characteristics of the intellectual sociability developed between those two important writers: on the one hand the European essayist suffering the necessities of his Brazilian exile and on the other the local writer whose extended web of relations enabled him to provide a living for a co-writer in need.
\end{abstract}

Keywords: Carpeaux; Ornellas; Correspondence; Literary relations

Em 1939 aportou no Brasil um exilado europeu cuja importância era desconhecida às pessoas que o receberam. Vindo da Bélgica, Otto Maria Carpeaux, nascido em Viena em 1900, era um dos principais intelectuais da oposição à política alemã do Terceiro Reich. Após um ano fora de seu país, o início da Segunda Guerra Mundial forçou-o a deixar também seu continente e procurar asilo na América. O crítico e pensador Alceu Amoroso Lima direcionou-o a Curitiba, cidade que Otto Maria Carpeaux logo trocou por São Paulo. Sem conhecer a língua do país e sem emprego, vendeu obras raras que havia trazido da Europa a fim de sobreviver. Uma carta a Álvaro Lins, o mais importante crítico literário da época, abriu-lhe as portas dos jornais do Rio de Janeiro, onde passou a publicar. Nos primeiros dois anos, escrevia artigos em francês, publicados, depois de traduzidos e revisados por, entre outros, Aurélio Buarque de Hollanda Ferreira. Ao longo da década de 1940, publicou várias coletâneas desses artigos e também uma Pequena bibliografia crítica da literatura brasileira. Também escreveu a História da literatura ocidental, que revisaria mais tarde e cuja primeira edição só sairia no final da década de 1950. Os empregos públicos que exerceu em sua primeira década no Brasil, como bibliotecário da Faculdade Nacional de Filosofia e da Fundação Getúlio Vargas, certamente lhe foram úteis nas pesquisas empreendidas para as próprias obras, porém não se constituíram em trabalhos duradouros. ${ }^{1}$

Assim, o convite de Manoelito de Ornellas para publicar artigos no Correio do Povo deve ter constituído notícia bem-vinda em um momento em que Otto Maria Carpeaux vivia apenas de sua atividade jornalística. Os

\footnotetext{
1 Os dados biobibliográficos de Otto Maria Carpeaux, bem como uma apreciação de sua atuação no Brasil, podem ser conferidos em Carvalho (1999, p. 15-73). Muitas dessas informações são corroboradas por Fernandes (2011). Filho de pai judeu e mãe católica, Carpeaux converterase ao catolicismo em 1932, dois anos depois de casar-se. Veio para o Brasil com um passaporte emitido pelo Vaticano e uma recomendação do papa Pio XII a Alceu Amoroso Lima (Tristão de Athayde).
} 
dois escritores não se conheciam pessoalmente. Ambos colaboravam para uma prestigiosa revista gaúcha da época, Província de São Pedro (1945-1957). Manoelito de Ornellas, nascido em 1903 em Itaqui, no Rio Grande do Sul, já publicara então livros de poemas, bem como ensaios de temática sul-rio-grandense, além de vários outros postos, ocupara um que devia colocá-lo em evidência junto aos intelectuais: de 1943 a 1945, fora diretor do Departamento Estadual de Imprensa e Propaganda do governo de Getúlio Vargas. Tal departamento, DEIP, era o braço local da censura, exercida em nível federal pelo DIP. Que apesar de haver exercido essa função malvista pelos democratas não tenha criado inimigos e que, pelo contrário, tenha até mesmo estendido a sua já vasta rede de relações devese certamente a sua personalidade envolvente ${ }^{2}$ e a sua capacidade de prestar "serviços na contenção de uma censura que poderia asfixiar a liberdade do pensamento impresso" (ORNELLAS, 1976, p. XIV). Um estudo sobre os intelectuais gaúchos e o Estado Novo aponta a intenção de "liberalização" no trabalho de Manoelito de Ornellas frente ao DEIP (GERTZ, 1912, p. 22). Nos anos seguintes, Gaúchos e beduinos (ORNELLAS, 1948) e outras obras consagrariam Manoelito de Ornellas nas letras rio-grandenses e nacionais. ${ }^{3}$

A obra de Manoelito de Ornellas e a de seus confrades rio-grandenses são frequentemente mencionadas por Otto Maria Carpeaux nas 17 cartas e bilhetes que aqui se comentam. Servem elas como um elo entre dois profissionais: ambos escrevem e têm, portanto, algo importante em comum. No entanto, por serem essencialmente ensaístas e escreverem para a imprensa do dia, que tem como uma de suas características predominantes a pressa na elaboração, tais cartas não constituem documentos genéticos, em que autores se consultam e aconselham a respeito da criação e redação de seus textos. As "perspectivas de exploração", aqui, apontam, em nosso entender, para a compreensão do perfil psicológico do missivista e para os bastidores da cena literária (aliás, Carpeaux não fazia distinção entre ensaio e literatura), jogando luz sobre relações entre escritores, sobre temas abordados e, portanto, sobre aspectos da história da literatura brasileira (cf. MORAES, 2006, p. 65).

A correspondência entre Otto Maria Carpeaux e Manoelito de Ornellas estendeu-se de uma data incerta em maio de 1949 até 6 de abril de 1953, dia em que Otto Maria Carpeaux anuncia sua próxima viagem à Europa, a primeira depois de 14 anos no Brasil. Possuímos apenas as cartas enviadas por Carpeaux. O catálogo existente no ALMAN (Acervo Literário Manoelito de Ornellas) não consigna nenhuma carta que tenha Carpeaux como destinatário e, no estado atual do arquivo, que se encontra em processo de recatalogação, torna-se difícil verificar se algum dos rascunhos de cartas deixados por Manoelito de
Ornellas ${ }^{4}$ se destinava a esse seu confrade e amigo do Rio de Janeiro. Por outro lado, não tivemos, para a presente investigação, acesso aos arquivos de Otto Maria Carpeaux depositados na Fundação Casa de Rui Barbosa. Dessa forma, pesquisas bibliográficas e conjeturas deverão, aqui, suprir o que não nos pode ser revelado por eventuais cartas ainda existentes.

As cartas e bilhetes de Otto Maria Carpeaux encontram-se praticamente todas em bom estado de conservação. Com raras exceções, são escritas em papelcarta para via aérea, tamanho A4, geralmente partido ao meio. Somente uma carta está datilografada, sendo as demais escritas com caneta-tinteiro e tinta azul. Pequenas rasuras são freqüentes, porém a letra de Carpeaux é regular e legível. Manchas amareladas, provavelmente de nicotina, ${ }^{5}$ não impedem a legibilidade. Os envelopes foram, presumivelmente, descartados.

Transcrevem-se, a seguir, trechos julgados significativos para a compreensão das cartas. Informações acrescentadas e trechos suprimidos são indicados por colchetes. Nos comentários, os nomes do remetente e do destinatário são abreviados para OMC e MO. A ortografia das cartas não foi atualizada, tendo sido mantidas também todas as outras particularidades e convenções da época.

[Data ilegível devido à perda de um fragmento do papel]: Rua República do Peru 101 Rio de Janeiro.

[...] Incluo nesta carta um artigo meu, publicado no dia 15 e talvez ainda desconhecido em Porto Alegre. [...] No futuro, pretendo $[\ldots]$ remeter os artigos quinzenais com a devida antecedência, de modo que possam sair no mesmo dia (ou ainda, em Porto Alegre, na $5^{\text {a }}$. Feira antes do domingo), de modo que se trata de colaboração especial e rigorosamente inédita para o 'Correio do Povo'. O próximo artigo será remetido ao correio no dia 30 de maio.

NB. Peço-lhe o favor de indicar à gerência do 'Correio do Povo' meu nome civil Otto Maria Karpfen [sobrenome duplamente sublinhado a mão]. Pois, 'Carpeaux' é pseudônimo que, legalmente, não existe. ${ }^{6}$

\footnotetext{
2 Veja-se a descrição que dele nos oferece Érico Veríssimo no prefácio que escreveu para a $3^{\mathrm{a}}$ edição de Gaúchos e beduínos (1976). Manoelito de Ornellas era, fisicamente, e talvez até mesmo por temperamento, o oposto do que mostram retratos e testemunhos de pessoas que conheceram Otto Maria Carpeaux.

3 Os dados biobibliográficos de Manoelito de Ornellas podem ser conferidos no site do DELFOS da PUCRS (http://www.pucrs.br/delfos/?p=ornellas) na nota da editora e no prefácio a Gaúchos e beduínos (ORNELLAS, 1976), bem como em Brasil, Moreira e Zilberman (Orgs., 1999, p. 123-124).

4 O ALMAN, cuja organização se iniciou com o próprio autor, é constituído de mais de 8.000 itens. Na catalogação trabalhou inicialmente a Profa. Alice Campos Moreira, seguida de outros docentes e alunos pesquisadores do DELFOS.

5 Segundo Ivan Junqueira, Carpeaux fumava quatro maços de cigarro em um dia de trabalho na redação (cf. CARPEAUX, 2005).

6 Fonte de consulta para esta, bem como para todas as demais cartas citadas: Biblioteca Central Irmão José Otão, PUCRS - DELFOS, Espaço de Documentação e Memória Cultural. As cartas, em processo de recatalogação, são identificadas por data de redação.
} 
Texto datilografado. Levando-se em conta as datas mencionadas no corpo da carta, bem como nas cartas subsequentes, a data provável desta fica em torno do dia 20 de maio de 1949. O endereço, ao alto, logo abaixo da data que se perdeu devido ao esgarçamento do papel, foi acrescentado à mão na caligrafia de OMC.

A carta se inicia com um agradecimento pela "possibilidade de estreitar os laços de amizade com os leitores rio-grandenses. Daí, pode o amigo avaliar minha alegria e gratidão." A gratidão manifestada na abertura da carta deve-se, provavelmente, à oferta de tornar-se articulista do Correio do Povo. No entanto, a afetuosidade da saudação e da despedida revela não se tratar do primeiro contato entre os dois escritores. A iniciativa terá sido tomada por MO. O "post scriptum" confirma a ideia de que se trata da primeira contribuição de OMC ao Correio do Povo, cuja administração, oficialmente, não o conhecia até então. OMC mudara o nome pela primeira vez em 1932, por ocasião de sua conversão ao catolicismo: de Otto Karpfen, passou a assinar Otto Maria Fidelis. Em 1941, começou a assinar seus artigos no Brasil com o pseudônimo Otto Maria Carpeaux. Sua naturalização ocorreu em 1944 (cf. CRONOLOGIA, p. 75).

As características do conteúdo, o fato de ser esta a única carta datilografada dentre as 17 cartas e bilhetes de OMC contidos no ALMAN - denunciando a provável intenção de expressar-se com clareza e sem equívocos a respeito de um assunto formal -, levam-nos a colocála em primeiro lugar na série. A rua onde OMC morava começa na Av. Atlântica e estende-se até o pé do Morro de São João, sendo quase exclusivamente residencial.

[29/05/1949] Meu caro e admirado amigo Manoelito de Ornellas:

Ontem chegou sua carta, bem uma das mais belas que recebi na minha vida, revelando em cada linha sua grande personalidade de escritor e homem. Não me quero porem referir aos termos elogiosos da sua carta porque não os mereço de maneira nenhuma. Tanto mais me alegra a perspectiva das nossas relações permanentes. E não vou perder ocasião nenhuma para dizer de voz alta quem é o escritor e homem Manoelito de Ornellas - amizade de que me ufano.

Um grande abraço de profunda gratidão do seu velho Otto Maria Carpeaux

NB. Naturalmente esquecí um assunto: sinto o horror de falar em dinheiro. Peço-lhe regularizar o assunto assim como entende bem. O José Olympio também é grande amigo meu.

A saudação ("caro e admirado amigo") e a despedida ("do seu velho") corroboram a convicção de que esta não é a primeira carta de $\mathrm{OMC}$ a $\mathrm{MO}$, ou pelo menos não representa o primeiro contato. $\mathrm{O}$ que $\mathrm{MO}$ havia produzido até então, como escritor, para ser elogiado por OMC? Os ensaios reunidos em vários livros e o importante Gaúchos e beduínos. O assunto "dinheiro" refere-se ao pagamento pelos artigos que OMC passará a remeter ao Correio do Povo.

[07/06/1949] Ilustre amigo Manoelito de Ornellas.

Agradeço muito sua carta aérea contendo o honorário pelo meu primeiro artigo no 'Correio do Povo'. Fiquei porem aflito ao saber que meus assuntos lhe causam trabalho. [...] Em todo caso, não é preciso remeter as importâncias, artigo por artigo: basta, no fim do mês. [...]

Também um bilhete, ainda mais breve que o anterior, esclarece a questão do dinheiro mencionada no "post scriptum" de 29/05/1949. Repete-se a cautela em relação ao dinheiro e a preocupação de não causar trabalho.

[18/07/1949] Meu caro e muito prezado Manoelito de Ornellas,

[...] Senti dolorosamente suas notícias quanto ao estado de saúde de sua senhora e seus próprios sofrimentos, lamentando tanto mais qualquer trabalho que eu possa causar. Realmente não era necessário mandar-me com tanta pressa aquele primeiro honorário; e daí em diante peço V. lembrar-se de mim apenas de dois em dois meses, o que basta perfeitamente.

[...] peço continuar a manter-me ao par da situação literária no Rio Grande [...]. Agora mesmo, trabalhando num seco mas talvez útil registro bibliográfico, lembrei-me muito dos escritores gaúchos do passado e do presente - Alcides Maya, Simões Lopes Neto, Erico Verissimo, Dionelio Machado, Moysés Vellinho, Felipe de Oliveira, Augusto Meyer, Raul Bopp, Viana Moog e (last but not least) do amigo ao qual dirijo esta carta (e há mais Eduardo Guimaraens e Alcides [sic] Wamosy e, antes, a geração do Parthenon Literário e tantos outros), de modo que eu também não compreendí absolutamente a falta de todos esses nomes na lista organizada por Alvaro Lins. Tive com ele duas conversas sérias sobre o assunto. [...]

Nessa ordem de idéias também só lhe posso agradecer pela continuação dos seus valiosíssimos estudos sobre a influência islâmica na formação do tipo riograndense. Esses estudos são particularmente importantes quanto à brasilidade desse tipo, sendo que influência semelhante também se observa em Minas e no Nordeste, sendo porem sensivelmente menor nos países hispano-americanos. Viajando diariamente para a cidade e passando pelo chamado 'Pavilhão Mourisco', sempre me lembro então curiosamente dos seus trabalhos [...].

Carta de página inteira. Pela primeira vez OMC se estende e torna-se mais pessoal. Curioso que o pedido de remessa de dinheiro dilata o prazo para uma periodicidade 
de dois meses. Nota-se seu nível de informação a respeito dos autores gaúchos e a preocupação de não magoá-los com a não inclusão de alguns nomes, possivelmente na Pequena bibliografia crítica da literatura brasileira (CARPEAUX, 1949). Álvaro Lins possivelmente o influenciou na indicação de nomes para essa obra até hoje importante. O "Pavilhão Mourisco", um prédio erguido na administração Pereira Passos, havia sido restaurante e depois biblioteca infantil, estando provavelmente abandonado à época da carta. Ficava em Botafogo - bairro de passagem para OMC, que morava em Copacabana - e foi demolido em 1952. Por outro lado, conhecido pela mesma alcunha era e é também o prédio central da Fundação Oswaldo Cruz, na zona norte da cidade.

[07/08/1949] [...] não vou ficar tão prolixo como da última vez. Estou porem reclamando sua resposta àquela minha última carta, tanto sobre o caso do Alvaro Lins como sobre o assunto muito mais interessante dos 'beduínos' no Rio Grande e das influências muçulmanas em Minas. Se você ainda não me respondeu, porventura, porque está novamente enfermo, também tenho o direito de reclamar notícias. Ainda não perdi toda esperança de fazer, um dia, uma visita em Porto Alegre; e estou simplesmente antecipando o estreitamento das relações pessoais.

[...] Mandei com certa antecedência o artigo sobre 'Jean Barois'. [...] O próximo artigo não vou porem remeter para o dia 21 e sim para o dia 28. A modificação justifica-se pela coincidência do bi-centenário de Goethe com o dia 28; estou de qualquer maneira com certa obrigação para escrever sobre o assunto, por mais batido que seja. Mas não vou repetir o que já foi dito mil vezes nem aventurar 'novas' teorias e sim escrever um artigo informativo. 'Variatio delectat'.

Enfim [...] agradeço a carta com Crs.\$ 400,00 que me chegou ontem. [...] preciso abordar outro assunto, embora com grande timidez e com aquele aborrecimento íntimo que inspiram todos os negócios de dinheiro. Recebi, até agora, pelo primeiro artigo publicado em maio pelo 'Correio', e agora por mais dois, não sabendo se esse pagamento se refere aos artigos dos dias 5 e 19 de Junho ou então aos artigos dos dias 10 e 24 de Julho. Nem perguntaria, se não fosse a situação que conhece: vivo sem emprego, só do trabalho literário e jornalístico, o que é heroísmo involuntário, aliás.

Todo o cuidado de OMC para não melindrar o amigo com o assunto da bibliografia o deixa ansioso por uma resposta. Se realmente chegou a visitar o Rio Grande do Sul não podemos depreender das cartas subseqüentes, nem de outras informações biográficas.

"Jean Barois" é o terceiro romance publicado por Roger Martin du Gard e seu tema é a perda da fé no mundo moderno. Sentir-se na obrigação de escrever sobre
Goethe mostra talvez a hesitação de OMC em relação aos temas alemães depois de seu exílio e da guerra.

A questão da remuneração para o homem sem emprego soa tanto mais pungente se considerarmos que OMC se encontra nesse momento há dez anos no Brasil.

[20/08/1949] [...] mando hoje, excepcionalmente, o artigo para sua residência particular, para fazê-lo acompanhar deste bilhete. Peço mil desculpas a você, não em meu nome, propriamente, mas em nome do 'Cruzeiro, Serviços Aéreos'. Tinham eles recebido o dinheiro, há um mês, mas não me avisaram de maneira alguma. E quando fui lá, ainda eram grosseiros. Que bela companhia! Mas sou mais uma vez, pelo menos indiretamente, causa de amolação para você.

Espero receber em breve a anunciada carta longa, [...].

Bilhete de 15 linhas, enviado ao endereço particular de MO junto com artigo. Novamente, a preocupação com os transtornos causados por questões de dinheiro. Manoelito, portanto, também escrevia cartas mais longas a $\mathrm{OMC}$, ou pelo menos as prometia...

[04/10/1949] [...] nesta hora [...], possível já mandaste pelo Correio os 400 cruzeiros correspondentes aos artigos dos dias 4 e 18 de Setembro. Peço, outra vez, mil desculpas pela amolação, mas minha situação é tão premente que não me fica outra saída: preciso lembrar-te que não recebi os outros 400 , relativos aos artigos dos dias 7 e 28 de Agosto! Como sabes, estou desempregado, 'chômeur', e o trabalho jornalístico constitui minha única fonte de rendas. Podes calcular as dificuldades por que estou passando. [...] Desculpa a grande pressa e o tom 'direto' desta carta. [...] Se pode providenciar a remessa dos 400 de Agosto ou dos 800 em uma vez, eu seria imensamente grato. O melhor caminho ainda é pelo correio, em carta transparente. Recebi seu recorte: senti-me muito honrado pela idéia de transcrever meu telegrama.

P.S. Desculpe a letra miserável; escrevo sempre e tudo à mão, e meus dedos estão inchados! [no cabeçalho da carta, à esquerda da data]

"Amolação" já se tornou um dos termos mais frequentes destes bilhetes e cartas. O termo "chômeur", significa "desempregado, sem trabalho", em francês, e é aqui uma tautologia. Singular o costume da remessa postal em envelope transparente! O telegrama mencionado pode ser o que consta do catálogo do DELFOS, porém o texto não foi localizado para o presente artigo.

"Escrevo sempre e tudo à mão" deve ser tomado relativamente, pois há indicações de que OMC também escrevia à máquina, quando se tratava de artigos ou textos mais longos. Por outro lado, é sabido que a esposa de $\mathrm{OMC}$, Helena, que abandonara uma carreira de cantora 
lírica na Europa para segui-lo, era quem datilografava os manuscritos de seus livros.

[06/10/1949] [...] ao receber sua boa carta do 4/10 fiquei muito envergonhado por lhe ter escrito. Perdoeme meu temperamento, que é mais tropical do que o dos brasileiros mais brasileiríssimos. Gracias por tudo!

Seu programa de viagens encheu-me de enorme satisfação, primeiro porque vejo que seu trabalho intelectual é devidamente apreciado no estrangeiro (o que só pouquíssimos brasileiros conseguiram no passado), e depois porque Você também irá à Europa; sei o que de insubstituível encerra essa experiência, principalmente a Espanha. Quanto ao meu "cheiro" com respeito a perigos de guerra, Você talvez tenha razão: em julho de 1919 insistí, contra o conselho de todos, em abandonar minha boa posição na Bélgica para ir à América; a guerra rebentou quando viajava, em agosto. Desta vez, a descoberta da bomba pelos russos me parece uma garantia de paz [...]. No entanto, seus projetos de viagem... também significam que vou perder, temporariamente, meu grande protetor e amigo no 'Correio do Povo'. Nesta qualidade como na de orientador literário Você é propriamente insubstituível... Espero com muita impaciência (já começa novamente o temperamento!!) suas notícias a respeito [do substituto] - e [...] sua gratíssima visita aqui no Rio.

A manifestação inicial de gratidão indica que o problema mencionado no bilhete anterior fora resolvido. MO viajava a convite do governo da Espanha e seu roteiro incluía Portugal.

A expressão "em julho de 1919" parece conter erro de data, pois não consta que OMC vivesse na Bélgica nessa época. Ainda assim, consideremos que nesse ano houve uma guerra entre a Hungria e a Romênia, consequência da Primeira Guerra Mundial, encerrada no ano anterior. Ambos os países reivindicavam regiões habitadas por seus grupos étnicos em territórios perdidos do Império Austro-Húngaro. A guerra envolvia a União Soviética e a antiga Tchecoslováquia e terminou ainda no mesmo ano.

A probabilidade é de que OMC quisesse referir-se a 1939. Neste último ano, em agosto (dia 24), foi assinado o tratado de não agressão entre a Alemanha e a União Soviética. O tratado implicava a divisão da Polônia, que foi invadida por Hitler no mês seguinte, fato que significou o início da Segunda Guerra Mundial. OMC fugira para a Bélgica poucos dias depois da anexação da Áustria, em março de 1938. Em 1939 emigrou para o Brasil (cf. CRONOLOGIA, p. 74-75).

Infelizmente não temos como verificar as qualidades de "orientador literário" que MO desempenhou junto a OMC. Podemos supor que lhe sugeria assuntos, mas não sabemos se tais sugestões incluíam modos de abordagem e redação.
[12/11/1949] [...] pelo mesmo correio mandei ao dr. Breno Caldas mais um artigo, destinado para o dia 20/11/49. Tomei a liberdade de incluir algumas linhas para ele mesmo, porque não quero mesmo que Você se preocupe com esse negócio danado de mandar dinheiro, etc.[...]

[21/11/1949] [...] recebí juntamente com sua última carta o aviso da remessa aérea [...]. Quero, porem, dizer que não escrevi por constrangimento: sinceramente, não quero que $\mathrm{V}$. se desse trabalho comigo. Em consideração disso, e também das suas projetadas viagens, escrevi (como V. já sabe) ao dr. Breno Caldas, pedindo que a administração do ‘Correio do Povo' faça no futuro as remessas. Agora, peço Você confirmar lá, no jornal, $[\ldots]$.

A projetada viagem de $\mathrm{MO}$ evidentemente ainda não se realizou. Ao escrever diretamente ao Dr. Breno Caldas, proprietário e presidente do Correio do Povo, e ao solicitar que MO confirme seu pedido de remessa direta dos futuros pagamentos, OMC está tomando providências para não ser esquecido durante a ausência de MO.

[27/11/1949] [...] recebi hoje sua carta (junto com outra, satisfatória, da gerência do 'Correio do Povo') e fiquei muito triste pela sua suspeita de que o novo modo de pagamento pudesse afrouxar os laços de amizade entre nós [...]. Só posso dizer que me ligam à sua pessoa os sentimentos de uma grande admiração intelectual e de profunda simpatia humana, [...]. Não sou, porém, o único aqui no Rio que pensa e sente assim. [...] seu nome está divulgadíssimo. [...] Acho que sua carreira literária lhe deve dar muita satisfação, acrescentandose os convites honrosíssimos e as viagens [...].

[24/03/1950] [...] recebi com imensa satisfação sua carta, por saber que não fui inteiramente esquecido. Respondo, porém, com atraso porque me jogou na cama por uns 8 dias uma daquelas gripes aniquilantes que só o bárbaro verão carioca é capaz de infligir.

Quanto ao 'Correio do Povo', está tudo em ordem. Leio aliás diariamente, na redação do 'Correio da Manhã' em que estou agora servindo como redator político, aquele excelente jornal gaúcho. Ainda me cabe exprimir minha grande satisfação quanto às notícias que me deu do seu livro; que já ocupa lugar tão destacado na sociologia histórica brasileira.

Falei com os Condés, que leram com efeito o artigo da Raquel. Vão mandar-lhe o 'Jornal de Letras' [...].

Aparentemente, MO encontra-se agora na Europa. Raquel deve ser Raquel de Queirós. Supõe-se que tenha escrito algo sobre Gaúchos e beduínos, à época o livro mais em evidência de MO. José Ferreira Condé (Caruaru, 1917 - Rio de Janeiro, 1971) foi um jornalista e escritor literário brasileiro. Dirigiu os jornais Pra Você e $O$ Jaú. Trabalhou no Correio da Manhã, na Editora José 
Olympio e na Agência Nacional. Fundou com os irmãos Elysio e João Condé o Jornal de Letras, que serviu de base para grandes escritores da literatura brasileira, como Carlos Drummond de Andrade, Clarice Lispector, Raquel de Queirós e vários outros. O Jornal de Letras, que interessaria consultar a respeito deste ponto, não está digitalizado.

[13/09/1950] [...] a visita que me fez um amigo gaúcho, trouxe-me a grande alegria de um abraço seu, à distância, mas também me lembrou vergonha minha: estou-lhe devendo, há muito, uma carta. Mas minha falta tem motivos sérios, que não são pretextos. Apesar de muitos esforços, o problema da minha vida não está resolvido até hoje; com 50 anos de idade, isso constitui experiência amarga. E nestes últimos tempos pre-eleitorais o trabalho de redação me absorve todas as noites. [...] Seu papel de liderança da inteligência sulina é inconfundível. Honra-me a amizade de um homem desses. $[\ldots]$

Nota-se o espaçamento temporal da correspondência, por parte de OMC, e a apreensão que o fato lhe causa. Suas palavras a respeito da própria instabilidade financeira são verdadeiramente pungentes e dispensam comentários.

[16/12/1950] [...] desta vez mando o artigo a V. pessoalmente, para poder juntar meus agradecimentos pela sua grande bondade para comigo durante este ano inteiro $[\ldots]$.

Escrevi nota merecidamente elogiosa sobre a revista que V. me remeteu. Mas ainda não pude publicá-la, [...]: o suplemento de 'O Jornal' está, 'graças' à falta de papel, reduzido a um mínimo; pelo mesmo motivo, o do 'Correio da Manhã' não está saindo há semanas; e de 'Letras e Artes' afastei-me voluntariamente (política!!) [...].

[28/02/1951] [Timbre à esquerda] Otto Maria Carpeaux [...] estou muito aflito por motivo da minha ausência forçada, quando Você me deu a honra de sua visita. Mas veja como minha vida está atrapalhada! Sobretudo essa última nomeação, que não pude declinar, por motivos óbvios, mas que me leva diariamente a subúrbio longínquo, foi para mim antes uma desgraça que um alívio.

O envolvimento político de OMC iniciou-se na Europa, e no Brasil foi muitas vezes tachado de esquerdista por partidos de direita e de conservador por partidos de esquerda. Sua condição de exilado exigia-lhe cautela nos primeiros anos, porém tornar-se-ia cada vez mais franco com o passar do tempo.

MO encontra-se de passagem no Rio à época da segunda carta. Após um primeiro desencontro, OMC oferece a alternativa do encontro no sábado, ou em seu horário de trabalho na redação do Correio da Manhã (Av. Gomes Freire, 471, $3^{\circ}$ andar).
[28/03/1951] [...] recebi sua gentilíssima carta com muita alegria e com um pouco de aflição - pois, estou realmente melancólico porque seu tempo não permitiu mais outro encontro conosco. $\mathrm{O}$ conhecimento pessoal com o amigo trouxe-me uma grande, uma imensa satisfação. Avalio agora muito mais que nunca seu grande valor intelectual, suas qualidades profundamente humanas, sua situação insubstituível em nosso panorama literário. [...] Envio, em folha separada, as respostas desejadas por "Reflets", revista de que gostei, aliás, muito. [...] Lembranças da parte de minha senhora, cumprimentos à sua família, [...].

A reação de OMC ao primeiro encontro pessoal com MO pode ser considerada francamente positiva. Nesse sentido, sua impressão não deve ter sido diferente daquela que tiveram de MO escritores como Érico Veríssimo (cf. VERÍSSIMO, 1976). A simpatia pessoal, a boa educação e a generosidade e inteligência de $\mathrm{MO}$ eram proverbiais e aparentemente jamais deixaram de surtir efeito.

[06/04/1953] [...] não sei se esta carta chegará em tempo às suas mãos, porque estou sem informações quanto à sua volta da Espanha. Contudo, preciso informar Você com respeito, agora, à minha viagem. Em 18 de abril embarcarei para a Europa, onde me demorarei até fins de setembro. Durante esse tempo, terei pouco tempo para escrever artigos literários, de modo que haverá alguma interrupção na minha colaboração para o 'Correio do Povo'.

Esperamos com muita impaciência os resultados, em forma de livro, dos seus estudos. Pois aqui tem muitos leitores e admiradores seus.

Da Europa, lhe darei notícias. Por hoje, um grande abraço do velho amigo Carpeaux.

Dois anos se passaram desde a visita de $\mathrm{MO}$ ao Rio de Janeiro até esta nova manifestação. Pode-se supor com certa segurança que algumas cartas escritas nesse intervalo se perderam, uma vez que nada há que revele qualquer desentendimento entre os dois missivistas. O extravio da correspondência é explicável pelo fato de MO encontrar-se na Europa por um tempo impreciso no período compreendido por essa lacuna epistolar.

Cumpre notar que este é o último bilhete de $\mathrm{OMC}$ a MO conservado no ALMAN. A viagem de OMC durou seis meses e incluiu Paris, Viena, Madri, Amsterdã e Nápoles (cf. CRONOLOGIA, p. 75). Ao que se sabe, retornou sem manifestar o desejo de permanecer na Europa.

$\mathrm{MO}$, por seu turno, foi demitido da Universidade Federal do Rio Grande do Sul, em cuja Faculdade de Filosofia ingressara em 1951, lecionando Literatura Latino-Americana e Cultura Ibérica. Ainda no ano de sua demissão, 1954, assumiu a cadeira de História da Arte na Faculdade de Filosofia em Florianópolis. Assim, na volta de OMC, sua função de intermediário no Correio do Povo se encerra. 
Também a colaboração de MO na revista Província de São Pedro ocorreu em um período distinto daquela de OMC. O primeiro colaborou de 1945 a 1951 enquanto as colaborações do segundo se estenderam de 1946 a dezembro de 1953 (cf. PROVÍNCIA, s/d), coincidentemente o ano em que se encerra a comunicação com MO.

Como "substituta da fala com o objetivo de uma troca dialógica", conforme Nickisch (1991, p. 12), "a carta apresenta uma das características de todo ato comunicativo: ela informa (objetivamente), apela (orientada para o destinatário) ou revela (orientada para o remetente)". ${ }^{7}$ As cartas de $\mathrm{OMC}$ a $\mathrm{MO}$ representam uma comunicação entre dois escritores apartados no espaço, que dificilmente teriam a oportunidade de falar-se de viva voz, levando-se em consideração a distância e as condições precárias da telefonia à época.

Por outro lado, a objetividade das informações contidas nas cartas de OMC a MO pode ser verificada quanto a muitos de seus aspectos. No entanto, para confirmar todos os fatos pessoais mencionados pelo remetente, necessitaríamos de mais testemunhos. As cartas se confirmam umas às outras quanto ao efeito apelativo que tiveram sobre $\mathrm{MO}$, que parece ter atendido fielmente a todos os pedidos de OMC e ter acreditado em seu correspondente distante. As cartas também revelam, dão a conhecer (em alemão, "manifestieren") a personalidade e os sentimentos de $\mathrm{OMC}$, alcançando esse efeito tanto por meio das palavras e dos assuntos abordados quanto pelas repetições e omissões. Assim, quando a objetividade aparente das cartas e bilhetes destoa das saudações e despedidas francamente afetuosas, quando preocupações de que por qualquer motivo possam surgir mal-entendidos entre os correspondentes, quando a falta de comunicação é justificada pelo receio de causar incômodos, é a personalidade complexa, do homem que vive uma situação precária e sempre provisória, que se manifesta.

As cartas de OMC também fornecem um retrato, embora tênue, de MO. Não sabemos até que ponto OMC conhecia o passado político de seu correspondente gaúcho. Sua atitude, no entanto, é sempre respeitosa, jamais expressando qualquer indagação a respeito de convicções políticas e religiosas. Assim como não revela as suas, OMC também não questiona a verdade íntima dos outros, preferindo sempre exaltar as qualidades intelectuais, as realizações literárias e a liderança intelectual exercida por MO em seu vasto círculo de relações literárias. ${ }^{8}$ Pode-se deduzir que as cartas de MO apresentassem teor semelhante,

\footnotetext{
Citação traduzida pelo autor do presente artigo.

8 A existência de tal círculo é fartamente ilustrada pelas numerosas cartas, remetidas por dezenas de correspondentes distintos e guardadas no ALMAN. A título de exemplo, citem-se cartas de Érico Veríssimo, Carlos Drummond de Andrade, Juana de Ibarbourou e numerosos outros brasileiros e estrangeiros.

9 Sobreasatividades eproduções deMO, ver $<$ http://www.pucrs.br/delfos/?p= ornellas>. Sobre OMC há uma excelente apreciação em Bosi (2013).
}

procurando sempre assegurar o correspondente de sua admiração e amizade. Se MO funcionou como conselheiro literário, como dá a entender uma das últimas cartas de $\mathrm{OMC}$, esta função foi exercida discretamente, e seus conselhos parecem ter sido aceitos sem objeção.

Levando-se em consideração todas as características mencionadas e o fato de que houve pelo menos um encontro pessoal entre os dois missivistas, pode-se considerar a correspondência entre $\mathrm{OMC}$ e $\mathrm{MO}$ o instrumento de uma relação bem-sucedida de sociabilidade literária, cujo encerramento ainda convém investigar por meio de outras pesquisas. Após a cessação dos contatos documentados, ambos os escritores ainda teriam uma vida produtiva relativamente longa: ${ }^{9}$ MO faleceu em 1969, aos 66 anos de idade; OMC alcançou a idade de 78 anos, tendo falecido em 1978.

\section{Referências}

BOSI, Alfredo. Sobre Otto Maria Carpeaux. In: Entre a literatura e a história. São Paulo: Editora 34, 2013. p. 405-421.

BRASIL, Luiz Antonio de Assis; MOREIRA, Maria Eunice; ZILBERMAN, Regina (Orgs.). Pequeno dicionário da literatura do Rio Grande do Sul. Porto Alegre: Novo Século, 1999.

CARPEAUX, Otto Maria. Pequena bibliografia crítica da literatura brasileira. Rio de Janeiro: Serviço de Documentação do MEC, 1949.

CARPEAUX, Otto Maria. História da literatura ocidental. São Paulo: Leya, 2011. v. I-IV.

CARPEAUX, Otto Maria. Ensaios reunidos: 1946-1971. Prefácio de Ivan Junqueira. Rio de Janeiro: Topbooks; UniverCidade, 2005. v. II. CARVALHO, Olavo de. Introdução a um exame de consciência e nota a esta edição. In: CARPEAUX, Otto Maria. Ensaios reunidos: 19421948. Rio de Janeiro: Topbooks; UniverCidade, 1999. v. I, p. 15-73. CRONOLOGIA da vida e da obra de Otto Maria Carpeaux. In: CARPEAUX, Otto Maria. Ensaios reunidos: 1942-1948. Rio de Janeiro: Topbboks; UniverCidade, 1999. v. I, p. 74-76.

DELFOS Espaço de Documentação e Memória Cultural. Manoelito de Ornellas. Acessível em: <http://www.pucrs.br/ delfos $/$ ? $p=$ ornellas $>$. Acesso em: 30/10/2013.

FERNANDES, Ronaldo Costa. História da literatura ocidental: a obra monumental de Otto Maria Carpeaux. In: CARPEAUX, Otto Maria. História da literatura ocidental. São Paulo: Leya, 2011, v. I. p. XIX-XLIII.

GERTZ, René. Intelectuais gaúchos e o Estado Novo brasileiro (1937-1945). História: debates e tendências. Porto Alegre, v. 13, n. 1, p. 19-32, jan./jun. 2013.

MORAES, Marcos Antonio de. Mário de Andrade: Epistolografia e processos de criação. Manuscrítica, Vitória, n. 14, p. 65-70, dez. 2006. NICKISCH, Reinhard M. G. Brief. Stuttgart: Metzler, 1991.

ORNELLAS, Manoelito de. Gaúchos e beduínos: a origem étnica e a formação social do Rio Grande do Sul. 3.ed. Prefácio de Érico Veríssimo. Rio de Janeiro: José Olímpio, 1976.

PROVÍNCIA de São Pedro: 1945-1957. Catálogo e texto. Porto Alegre: PUCRS-CNPq-FAPERGS, s/d. CD-ROM.

VERÍSSIMO, Érico. Manoelito de Ornellas. In: ORNELLAS, Manoelito de. Gaúchos e beduínos: a origem étnica e a formação social do Rio Grande do Sul. Rio de Janeiro: José Olympio, 1976. p. XVII-XXVII.

Recebido: 01 de novembro de 2013

Aprovado: 13 de novembro de 2013

Contato: perth@pucrs.br 